\title{
Round Robin comparison II of the capabilities of various thermographic techniques in the detection of defects in carbon fibre composites.
}

\author{
by D.P. Almond*, R.J. Ball*, A. Dillenz ${ }^{* *}$, G. Busse ${ }^{* *}$, \\ J.-C. Krapez ${ }^{* * *}$, F. Galmiche ${ }^{* * * *}$ and X. Maldague ${ }^{\star \star * *}$
}

*Department of Engineering and Applied Science, University of Bath, Bath, BA2 7AY, UK.

**IKP, Universität Stuttgart, Pfaffenwaldring 32, D-70569 Stuttgart, Germany.

${ }_{* * *}$ Structure and Damage Mechanics Department, ONERA, BP 72, 92322 Châtillon cedex, France.

$\star \star \star \star$ Université Laval, Cité Universitaire, Quebec, Canada, GIK $7 P 4$.

\begin{abstract}
:
Four samples of carbon fibre reinforced composite which contained impact damage sites, verified by ultrasonic C-scans, have been studied independently by the groups participating in this second QIRT Round Robin exercise. The samples were selected from a much larger collection because long pulse heating transient thermography (Bath) had failed to detect the presence of the defects at the front (impact) faces. The other techniques employed were: optical lock-in thermography and ultrasound lock-in thermography (Stuttgart); pulsed thermography using the emerging contrast technique (ONERA) and pulsed phase thermography (Laval). Only ultrasound lock-in thermography was successful in detecting the defects at the front faces.
\end{abstract}

\section{Introduction}

This second QIRT Round Robin exercise, devoted to investigating the relative merits of different thermographic techniques in detecting and characterising impact damage in carbon fibre composites, arose from a presentation at QIRT 98 on the detection of impact damage in thick carbon fibre composites [1]. At this presentation it was reported that a total of 88 samples, with thicknesses ranging from $3.44 \mathrm{~mm}$ to $16 \mathrm{~mm}$, had been examined using the long pulse heating transient thermography technique and that impact damage in 19 samples had not been detected at the impact face. As in practice it is only the front face (impact face) that is accessible to an inspector, of an aircraft structure for example, these failures cast doubt about the reliability of thermography in this important application. It was decided to circulate a number of these 19 samples amongst the participants of this round robin exercise as a challenging test of their particular thermographic techniques for defect detection.

\section{Samples}

The samples, produced by Airbus UK (formerly British Aerospace) were plates of carbon fibre composite $100 \mathrm{~mm} \times 150 \mathrm{~mm}$, three were $3.44 \mathrm{~mm}$ thick and the fourth was $6.88 \mathrm{~mm}$ thick. They were formed by 4 and 8 , respectively, blankets where each blanket had a $( \pm 45,0)$ lay-up. The samples were impacted using a Rosand Instrumented Falling Weight Tester, Type 5 . The impacts were produced by a $20 \mathrm{~mm}$ diameter hemispherical striker at impact velocities below $3 \mathrm{~ms}^{-1}$. By eye, there wás little or no sign of impact damage at the impact surface but a delamination blister was evident at the back surface of each sample, as is typical of this type of damage. Each sample was imaged using ultrasonic C-scan to assesi the extent of the delamination damage caused by the impacts. The results obtained for the four samples are listed in table 1.

\section{Long pulse heating transient thermography}

The samples were heated for 3 seconds using two 500 watt quartz halogen flood lampl mounted horizontally each side of the sample at a distance of $14 \mathrm{~cm}$. An AGA Agema Thermovision 750 camera was used to record images as the samples cooled down when the 
lamps were switched off. The camera had an InSb detector with a thermal resolution of $0.2^{\circ} \mathrm{C}$ at $30^{\circ} \mathrm{C}$ and a spectral response of $2-5.6 \mu \mathrm{m}$. The images were collected by a frame grabber in $256 \times 248$ pixel 8 bit digital form. For each sample, no evidence of the impact damage was obtained from the front face of the sample although clear iages of damage were obtained from the back faces.

\section{Pulsed thermography using the emerging contrast technique}

The samples were heated by a flash lamp and a FPA IR camera (Amber $4128,217 \mathrm{~Hz}$, $<10 \mathrm{mK}$ NETD) was used to record resulting thermal images. The lamp and camera were located on the same side of the sample, first at the rear side and then at the impacted side.

As a first step the principal diffusivities of the composite material were measured. For this purpose the sample numbered 1.2 was used. The grid method [2] was used in a region free from any defect to get simultaneously the values of the two principal diffusivities: one in the through-thickness direction and the other in the direction perpendicular to the grid pattern. A flash lamp was used for heating and the camera for temperature measurement of the rear surface. A grid mask with $15 \mathrm{~mm}$ pitch was placed between the lamp and the sample in order to generate a periodic heating pattern. The temperature field on the rear side of the sample was processed through a Fourier transform. The parameter identification was performed through the joint analysis of the first two Fourier components [2]. The results were $0.38 \mathrm{~mm}^{2}$ $\mathrm{s}^{-1}$ for through-thickness diffusivity and $1.9 \mathrm{~mm}^{2} \mathrm{~s}^{-1}$ for diffusivity along the length of the sample. By rotating the grid by $90^{\circ}$ the diffusivity value of $1.0 \mathrm{~mm}^{2} \mathrm{~s}^{-1}$ for the third direction was obtained. Measurement uncertainty was of the order of 3-5\%. These results highlight the composite thermal anisotropy. The square root of the anisotropy ratio, $1.0 / 0.38$ or $1.9 / 0.38$, indicates that it is 1.6 to 2.2 times harder to detect defects in this type of material as compared to isotropic materials. In other words, the critical diameter/depth ratio for a safe detection of delaminations is 1.6 to 2.2 higher. The through-thickness diffusivity value was necessary to get the defect depth maps that will be later described.

The samples were tested as received, i.e. without any additional coating that would help to increase either the absorptivity or the infrared emissivity. It was no surprise that the defects were most easily seen from the rear side. Fig. 1 is an infrared image taken from the sequence that was recorded with sample 1.2 (1.7 s after flash heating). Also plotted is the defect map as obtained through the analysis of the contrast evolution at each pixel. Depth identification was performed by applying the emerging contrast method together with the through-thickness diffusivity data $[3,4]$. According to this approach, the depth map is less affected by lateral diffusion. The classical butterfly shape of the multi-delamination defect is clearly revealed. Similar results were obtained on samples 2.1, 1.6 and 3.6.

However, when flash thermography was applied on the impacted side the defects were not detected, fig. 2. The optical and thermal non-uniformity of the surface was too high causing the contrast induced by the delaminations to be hidden in a mess of artefacts related to the woven structure. The periodic structure of the composite fibre bundles in the $90^{\circ},+45^{\circ}$ and $-45^{\circ}$ directions can be easily distinguished. In most cases there was higher contrast at the centre of the image at the location of the impact. However this contrast level was of the vame magnitude as the contrast that stems from the structural temperature non-uniformity. for this reason, the emerging contrast method faces great difficulties in providing clear images of the defects. On the right of Fig 2, i.e. the defect depth map, is essentially noise. It Is reasonable to conclude, that flash thermography, when performed on the impacted face, is hefficient for detecting the damage in the samples of this Round Robin series.

\section{Pulsed Phase thermography'}

Pulsed phase thermography was introduced in 1996 [5]. This technique was described as 9 link between pulsed thermography and lock-in thermography Data acquisition is the same 4 fo for flash or pulsed thermography but signal processing is employed to generate phase 
images. Two Balcar FX60 photographic flash lamps were used to apply a brief and powerful energy pulse to the surfaces of the samples. Just after the thermal pulse, a series of infrared images of the surfaces were recorded by a Cincinnati Electronics IRC-160in infrared camera [6]. The Fourier transform of the temporal evolution of the temperature $T(t)$ of each pixel, where $t$ is the time, was calculated [7]:

$$
\text { Fourier_Transform }[T(t)]=\text { FTT }(f)={ }_{-x}^{+x} T(t) e^{-i 2 \pi t f} d t=A(f) e^{i \phi(f)}
$$

where FTT(f) is the discrete Fourier transform of $T(t), A(f)$ is the amplitude of the result and $\phi(f)$ its phase. The phase images give a generally good contrast image that permits the detection of the defects. The main advantages of this method are that phase is less affected by heating non-uniformity and maximum depth penetration of the phase is about twice the depth penetration of the amplitude [8].

The CFRP samples showed a high reflectivity even in the infrared domain, which was a major problem for pulsed phased thermography. Due to it being unacceptable to paint the samples, tapes were applied and then the samples were painted black. This provided an reduce in reflectivity, however, the resolution of the acquisition was reduced. The lamps illuminated the samples for $8 \mathrm{~s}$ in order to obtain enough contrast. The image acquisition step was $\Delta t=0.07 \mathrm{~s}$ for $24 \mathrm{~s}$. Fig. 3 shows the phase images for two different samples, each computed for the $f=0.125 \mathrm{~Hz}$ component of the thermal transient. Both images show the only observable sub-surface defects. The visible part of the defect is around $4 \mathrm{~mm}$ wide. On each image we can observe a triangular defect which is far bigger than a visible surface defect. Using the thermal diffusion length at the above frequency it is possible to estimate that the observed structure is at a depth of about $1 \mathrm{~mm}$. It is impossible to know if these structures are due to an impact or if they came from an artefact caused by the sample's inherent inner structure.

\section{Optical Lock-in thermography}

Two modulated lamps (1000 W each) illuminated the samples at a frequency of $0.03 \mathrm{~Hz}$ for less than 3 minutes while the thermography system (AGEMA 900 Lock-in) acquired images in the wavelength range $8-12 \mu \mathrm{m}$ at a rate of $7.5 \mathrm{images} / \mathrm{s}$. The basic idea of lock-in thermography [9] is to use modulated heating to induce a thermal wave that propagates into the inspected component. As this wave undergoes reflections at boundaries, the temperature modulation at the surface is modified by thermal waves coming back from the inside of the component. An indicator for such effects is the phase angle between energy deposition and local thermal response. If the temperature field is monitored during the modulated illumination with a thermography camera, Fourier analysis performed at each pixel provides magnitude and phase of the local response. These two quantities can be displayed as two different images. The magnitude image is affected by inhomogenities of optical surface absorption, infrared emission and distribution of optical illumination. However, in the phase image each of these effects is eliminated. The range of subsurface detection using thermal waves depends on the frequency of modulation, it increases with its inverse square root. Signal phase also has the advantage that its depth range is almost twice that of signal magnitude.

The images shown in fig. 4, obtained of the front and rear faces of sample 2.1, are typical of those obtained from all of the samples using optical lock-in thermography. The impact damage was only seen from the back side of the sample despite the thermal penetration depth (2 $\mathrm{mm}$ at a frequency of $0.03 \mathrm{~Hz}$ in carbon fibre reinforced polymers) theoretically allowing the detection of detects at depths of $4 \mathrm{~mm}$ using the phase angle. 


\section{http://dx.doi.org/10.21611/qirt.2000.065}

\section{Ultrasound Lock-in Thermography}

For Ultrasound lock-in thermography [10] an ultrasound excitation source with a frequency of $20 \mathrm{kHz}$ and a maximum power of $2000 \mathrm{~W}$ was used to excite the samples. The transducer was coupled to the samples using a polymer foil to both decrease the acoustic impedance mismatch and protect the sample against mechanical damage.

Internal excitation is produced by the ultrasound which only heats up defects. Another difference between internal and external excitation regards the thermal penetration depth. In a reflection configuration, as used for optical lock-in thermography the incoming thermal wave interferes with the reflected thermal wave coming back from existing boundaries. This leads to interference effects and therefore to a limited thermal penetration depth. With ultrasound excitation the set-up is a transmission configuration and hence is less limited by
defect depth.

The images shown in fig. 5 obtained again of the front and rear faces of sample 2.1, are typical of those obtained from all of the samples using ultrasound lock-in thermography. The approximately circular features at the centres of the figures, obtained at both front and back faces, are very similar to the impact damage images obtained earlier by ultrasonic C-scan.

\section{Conclusions}

None of the four variants of thermography in which the sample surface is heated photothermally was successful in detecting the impact damage in any of the samples from the front (impact) faces. Reasons for this failure may include the strong thermal anisotropy and complex structure of carbon fibre materials that seriously affects thermal diffusion to and from a defect. In addition, impact damage delaminations are concentrated towards the back face of a sample and these delaminations may have acted as rather modest thermal contact resistances. Ultrasound lock-in thermography, however, showed clear damage images from both front and back sides of all the tested samples. In the ultrasound excitation case, the defect becomes the heat source, rather than an interceptor or reflector of heat arriving from the surface. It appears that whilst the delamination damage acted as a rather poor thermal interceptor or reflector, it became an effective heat source when stimulated ultrasonically. These results cast serious doubt about the overall reliability of thermographic techniques that rely on surface heating for the detection of impact damage in composites whilst underlining the potential value of ultrasound lock-in thermography.

\section{Acknowledgements}

The authors are grateful to J. Ball of Airbus UK, Filton, UK, (formerly British Aerospace) for allowing the samples to be used in this Round Robin exercise.

\section{References}

[1] R.J. Ball, D.P. Almond; "The detection and measurement of impact damage in thick carbon fibre reinforced laminates by transient thermography" NDT\&E Int., 31, 1998, p.
$165-173$.

[2] J.-C. Krapez; "Simultaneous measurement of in-plane and out-of-plane diffusivity by using a grid-like mask". 5th Int. Workshop on Advanced Infrared Techn. and Appl.,

[3] J.-C. Krapez, D. Balageas; "Early detection of thermal contrast in pulsed stimulated infrared thermography". Quantitative Infrared Thermography (QIRT 94), Sorrento, Italy, 23-26 August 1994, Eurotherm series 42 - EETI ed. Paris, 1995, pp. 260-226.

[4] V. Vavilov, D.P. Almond, G. Busse, E. Grinzato, J.-C. Krapez, X. Maldague. S. Marinetti, W. Peng, V. Shirayev, D. Wu; "Infrared thermographic detection and characterization of impact damage in carbon fibre composites: results of the round robin test", QIRT'98, Quantitative Infrared Thermography, Lodz (Poland), Sept. 7-10, 1998, Eurotherm Series 60 , pp. 43-52. 
http://dx.doi.org/10.21611/qirt.2000.065

[5] X. Maldague, S. Marinetti; "Pulse Phase Infrared Thermography", J. Appl. Phys., 79, 1996, p. 2694-2698.

[6] X. Maldague; Nondestructive evaluation of materials by infrared thermography, Springer-Verlag. London, 1993, p.207

[7] F. Galmiche, X. Maldague; "Pulsed Phased Thermography", Thermography Handbook for NDE, ASNDT, In Print, 2000.

[8] V.P. Vavilov, S. Marinetti; "Pulsed Phase thermography and Fourier-analysis thermal tomography", Russian J. NDT, 35, 1999 p.134-145.

[9] G. Busse, D. Wu, W. Karpen; "Thermal wave imaging with phase sensitive modulated thermography", J. Appl. Phys. 71, 1992, p 3962-3965.

[10] J. Rantala, D. Wu, G. Busse; "NDT of polymer materials using lock-in thermography with water coupled ultrasonic excitation", NDT\&E Int. 31, 1998, p. 43-49. 


\section{http://dx.doi.org/10.21611/qirt.2000.065}

Table 1. Ultrasonic C-scan measurements of impact damage in Round Robin samples

\begin{tabular}{|c|c|c|c|}
\hline Sample Number & Thickness $(\mathrm{mm})$ & Impact Energy $(\mathrm{J})$ & C-scan damáge area $(\mathrm{cm} 2)$ \\
\hline 1.2 & 3.44 & 3.99 & 3.05 \\
\hline 1.6 & 3.44 & 4.14 & 3.15 \\
\hline 2.1 & 3.44 & 4.09 & 2.2 \\
\hline 3.6 & 6.88 & 8.87 & 5.85 \\
\hline
\end{tabular}
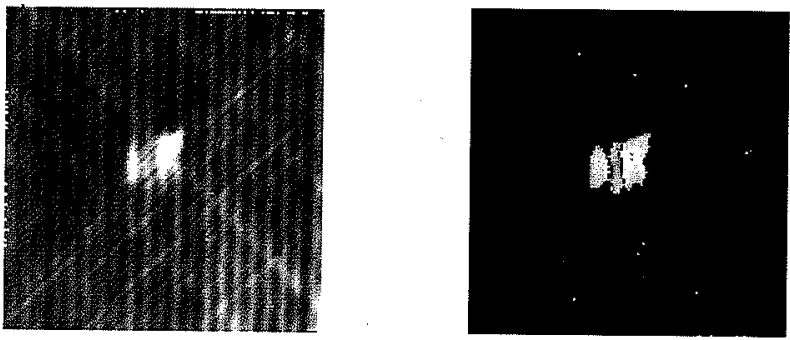

$2000 \mu \mathrm{m}$

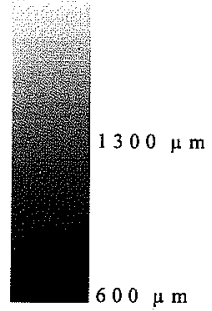

Fig. 1. Sample 1.2 back face infrared image (ONERA) taken $1.7 \mathrm{~s}$ after flash (left). Delamination map as obtained with the emerging contrast method (right).
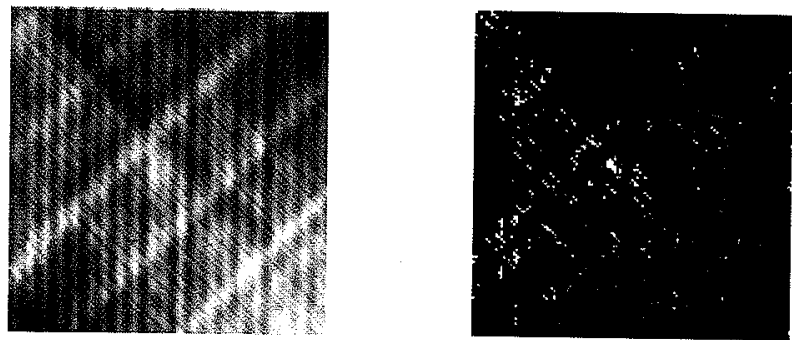

$1400 \mu \mathrm{m}$

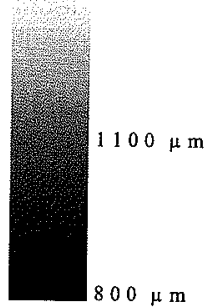

Fig. 2. Sample 1.2 impacted side infrared image (ONERA) taken $3.7 \mathrm{~s}$ after the flash (left). Delamination map as obtained with the emerging contrast method (right).
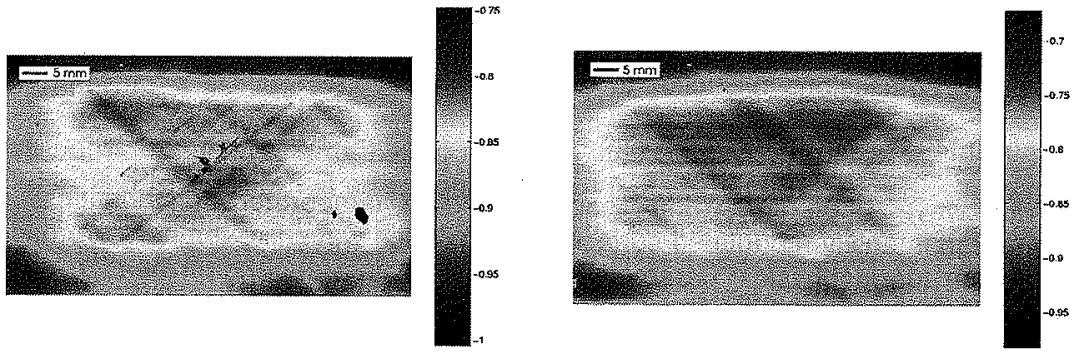

Fig.3. Phase images (LAVAL) for 2 different samples at $0.125 \mathrm{~Hz}$. 